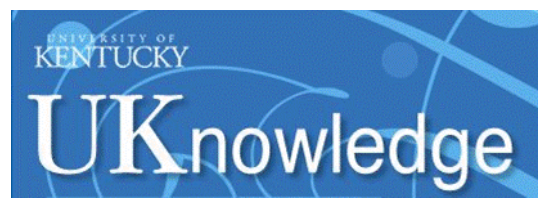

University of Kentucky

UKnowledge

\title{
Inhibitory deficits in children with attention-deficit/hyperactivity disorder: Intentional versus automatic mechanisms of attention
}

\author{
Mark T. Fillmore \\ University of Kentucky, fillmore@uky.edu \\ Richard Milich \\ University of Kentucky, richard.milich@uky.edu \\ Elizabeth P. Lorch \\ University of Kentucky, elorch@uky.edu
}

Follow this and additional works at: https://uknowledge.uky.edu/psychology_facpub

Part of the Child Psychology Commons

Right click to open a feedback form in a new tab to let us know how this document benefits you.

\section{Repository Citation}

Fillmore, Mark T.; Milich, Richard; and Lorch, Elizabeth P., "Inhibitory deficits in children with attentiondeficit/hyperactivity disorder: Intentional versus automatic mechanisms of attention" (2009). Psychology Faculty Publications. 85.

https://uknowledge.uky.edu/psychology_facpub/85

This Article is brought to you for free and open access by the Psychology at UKnowledge. It has been accepted for inclusion in Psychology Faculty Publications by an authorized administrator of UKnowledge. For more information, please contact UKnowledge@lsv.uky.edu. 
Inhibitory deficits in children with attention-deficit/hyperactivity disorder: Intentional versus automatic mechanisms of attention

Digital Object Identifier (DOI)

$10.1017 /$ S0954579409000297

Notes/Citation Information

This article was made available online April 1, 2009. 


\title{
Inhibitory deficits in children with attention- deficit/hyperactivity disorder: Intentional versus automatic mechanisms of attention
}

\author{
MARK T. FILLMORE, RICHARD MILICH, AND ELIZABETH P. LORCH \\ University of Kentucky
}

\begin{abstract}
Application of theoretically based tasks to the study of the development of selective attention has led to intriguing new findings concerning the role of inhibitory mechanisms. This study examined inhibitory mechanisms using a countermanding task and an inhibition of return task to compare deficits in intentionally, versus reflexively, controlled inhibition of attention in children with attention deficit hyperactivity disorder. Fifty children with attention-deficit/ hyperactivity disorder (ADHD) were classified into one of three subtypes: predominantly inattentive (ADHD/PI), combined (ADHD/C), and those children with ADHD/C who also met criteria for comorbid oppositional defiant disorder (ADHD/C + ODD). The groups were compared to a comparison group of children $(n=21)$. The countermanding task showed that the ADHD groups required more time to inhibit responses and this impairment did not differ among subtypes. With respect to reflexively controlled inhibition, compared with controls ADHD/C and ADHD/C + ODD groups showed impaired reflexive inhibition, whereas the ADHD/PI group was considerably less impaired. The findings highlight a dissociation between the two forms of inhibitory deficits among children with the inattentive subtype, and raise the possibility that the efficient operation of reflexive inhibitory mechanisms might be necessary for the development of effective intentional control of inhibition.
\end{abstract}

In the field of developmental psychopathology, the concept of inhibitory control has become a particularly important construct. As part of typical cognitive development, the achievement of inhibitory control allows for efficient, goaldirected behavior (Barkley, 1997). Further, the failure to achieve age-appropriate inhibitory control is recognized as being an element critical to understanding several childhood behavior disorders. In particular, there is now widespread agreement that problems in inhibitory control represent a core deficit among children with attention-deficit/hyperactivity disorder (ADHD; Barkley, 2006; Nigg, 2006). However, despite

This research was supported by Grants DA021027 and DA005312 from the National Institute on Drug Abuse.

Address correspondence and reprint requests to: Mark Fillmore, Department of Psychology, University of Kentucky, Lexington, KY 40506-0044; E-mail: fillmore@ uky.edu. the recognized importance that deficits in inhibitory control assume in explaining the behavioral problems of children with ADHD, the literature on inhibitory control in typically developing children suggests important questions that have not been addressed in research on ADHD. For example, the developmental literature suggests that inhibitory control processes play an important role in regulating other cognitive functions, such as the allocation of attention (Luna, Garver, Urban, Lazar, \& Sweeney, 2004). However, in studies of ADHD, problems in inhibitory control and attention are both considered important, but often represent distinct areas of investigation. In addition, in the cognitive literature important distinctions are made between automatic (i.e., reflexive) and intentional mechanisms underlying inhibitory control (Marzi, 1999). This distinction is especially important from a developmental perspective because research suggests that automatic processes should predate, and perhaps lay the 
foundation for, more intentional control mechanisms (Aksan \& Kochanska, 2004). The distinction between automatic and intentional mechanisms of behaviors is also well recognized in the ADHD literature (e.g., Huang-Pollock, Carr, $\&$ Nigg, 2002). However, the question of whether it is important to differentiate automatic and intentional mechanisms specifically with respect to understanding inhibitory problems among children with ADHD has not been well examined. The answers to these two questions may differ depending on which subtypes of ADHD are investigated, given that attention and inhibitory problems are theorized to be differentially important in explaining problems associated with the combined and inattentive subtypes of ADHD (Milich, Balentine, \& Lynam, 2001). The present study was designed to address each of these three issues.

ADHD is a heterogeneous developmental disorder that is characterized by a combination of core symptoms that include impulsivity, poor attention, and hyperactivity (Barkley, 2006). The heterogeneity of the disorder is evident in the Diagnostic and Statistical Manual of Mental Disorders_Fourth Edition (DSM-IV; American Psychiatric Association, 1994) diagnostic criteria, which recognize three subtypes based on the relative expression of hyperactive/impulsive and inattentive symptoms: predominantly hyperactive-impulsive $(\mathrm{ADHD} / \mathrm{PH})$, predominantly inattentive (ADHD/PI), and combined (ADHD/C). Impulsivity is evidenced by a failure to delay responses or to consider possible consequences for actions, whereas poor attention is often observed as a lack of consideration for detail, failure to sustain attention, and a susceptibility to distraction by irrelevant stimuli.

Although the symptoms that characterize ADHD and its subtypes are well established, the specific deficits in fundamental behavioral and cognitive mechanisms that might account for these symptoms remain elusive despite considerable neuropsychological research effort (for reviews, see Barkley, 2006; Nigg, 2006). To better understand these mechanisms, research has shifted away from the use of traditional neuropsychological tasks to the use of more focused assessments of specific cognitive mechanisms that subserve higher order executive functions (Nigg, 2006). One mechanism that appears to be impaired in children with ADHD involves the ability to inhibit or suppress prepotent behavioral actions (Barkley, 2006; Tannock, 1998), impairment that is suspected to be involved in impulsivity. The tasks used to detect impairments of inhibitory control are based on cognitive theories concerning the role of inhibitory mechanisms in the regulation and control of thought and action (Logan, 1994; Logan \& Cowan, 1984; Miller, Schaffer \& Hackley, 1991). Two of the most common tasks, the stop-signal and go/no-go task, are simple reaction time measures in which the subject must manually respond to go targets (e.g., press a button), but inhibit this response when no-go stimuli are presented. With respect to cognitive development, studies using these tasks find that normally developing children demonstrate inhibitory control as early as 3 years of age, with this ability becoming maximally efficient at about 12 years of age (Aksan \& Kochanska, 2004; Durston et al., 2002. However, for children with ADHD, these same tasks demonstrate pronounced deficits in the ability to inhibit behavior that are evident throughout adolescence (e.g., Oosterlaan \& Sergeant, 1996; Schachar, Tannock, Marriott, \& Logan, 1995).

More recently, assessments of inhibitory control in children with ADHD have examined the inhibition of ocular responses (O'Driscoll et al., 2005). Imaging studies have found abnormal functioning in the frontal-striatal system and the frontal eye fields of children with ADHD (e.g., Castellanos et al., 1996). These regions are strongly implicated in the control of many ocular functions, including the inhibition of saccades (e.g., Ro, Farne, \& Chang, 2003; Schall, 2004). Thus, identifying potential inhibitory deficits in the control of eye movements (i.e., saccades) could provide a better understanding of the mechanisms underlying the problems of attention in these children.

Assessments of ocular control typically include antisaccade and countermanding tasks that require subjects to inhibit saccades to the sudden appearance of stimuli that otherwise trigger a reflexive saccade to their location. In children with ADHD, these tasks demonstrate impairments in the ability to inhibit these types of saccades (e.g., Hanishch, Radach, Haltkamp, Herpertz-Dahlmann, \& Konrad, 2006; Klein, 
Raschke, \& Brandenbusch, 2003). However, some studies using these tasks have failed to demonstrate impairments in children with ADHD (e.g., Rommelse et al., 2007). Still other studies have noted that the impairments might not be uniformly observed across the various subtypes of the disorder (O'Driscoll et al., 2005), suggesting that subtypes might differ in terms of specific elements of ocular control that are deficient. Such evidence might be used to better characterize the individual subtypes in terms of the specific nature of the inhibitory deficits involved. Improvement of subtype characterization is also particularly important because the diagnostic validity of the subtypes has been a source of controversy for some time. For example, it has been argued that the ADHD/PI subtype has little in common with $\mathrm{ADHD} / \mathrm{C}$ in terms of impulsive behavior and cognitive impairments, suggesting that the inattentive diagnosis might not represent a subtype of ADHD but rather a distinct disorder itself (Barkley, 2001; Diamond, 2005; Milich et al., 2001). However, evidence contrasting inhibitory impairments between $\mathrm{ADHD} / \mathrm{C}$ and ADHD/PI subtypes has been limited because studies are often based on samples in which there were no subtype diagnoses, or from samples comprised only of the combined subtype, or from ADHD/PI groups contaminated by the inclusion of "subthreshold" ADHD/C children (Milich et al., 2001).

Although studies of ADHD have demonstrated deficits in inhibitory mechanisms involved in ocular function, there remain many questions concerning the specific nature of the inhibitory mechanisms that might be impaired in the various subtypes. Inhibitory control is not a unitary construct. A fundamental distinction among inhibitory mechanisms that has yet to be addressed in this research concerns whether the mechanism is intentionally controlled or is reflexive, occurring automatically (Marzi, 1999; Mayer, Seidenberg, Dorflinger \& Rao, 2004; Shimojo, Hikosaka, Miyauchi, 1999). Intentional inhibitory mechanisms are under control of the individual and operate at the level of awareness (i.e., endogenously initiated). By contrast, automatic inhibitory mechanisms occur without intention in a reflexive manner evoked by the presence of irrelevant stimuli (i.e., exogenously initiated). This distinction is important from a develop- mental perspective because these mechanisms might not develop in parallel and might be interdependent. For example, some theories argue that the emergence of reflexive attentional mechanisms that inhibit the influence of distracting stimuli are necessary for the normal development of intentionally controlled inhibition and working memory (Aksan \& Kochanska, 2004; Luna et al., 2004).

The countermanding task emphasizes intentional inhibition of an ocular response to a visual target. Prior to each target, participants fixate on a central point and then execute a saccade to the target when it appears. These saccades must be inhibited (i.e., countermanded) on trials in which an auditory stop signal also is presented. As such, the countermanding task measures the ability of a subject to intentionally inhibit the tendency to make a reflexive saccade toward the sudden appearance of a visual stimulus. A recent study that used the countermanding task found that children with ADHD displayed longer stopsignal reaction times (SSRTs) compared with controls, indicating that their ability to intentionally inhibit an ocular response is impaired (Hanishch et al., 2006). The evidence is important because it suggests a deficient ability to intentionally inhibit the allocation of attention to irrelevant stimuli, which could account for the increased distraction that is characteristic of ADHD.

With regard to automatic inhibitory mechanisms of attention, there has been little research examining deficits of this nature in children with ADHD. One approach used to study reflexive inhibitory mechanisms in developmental and clinical research involves the inhibition of return (IOR) task (Klein, 1988, 2000; Klein \& MacInnes, 1999), and is based on a phenomenon first documented by Posner and Cohen (1984). When scanning a visual environment, attention is directed over different locations until a stimulus of interest is detected. A cue or signal that draws attention to a specific location can facilitate the detection of an object that is subsequently presented at that same location. This facilitation effect is attributed to a reflexive shift of attention toward the previously attended location. However, the facilitation persists for only a brief period of time. Once attention has been directed away from a location for a sufficient period, the time required for attention to return to that original location actually 
increases relative to the time required to direct attention to a new, previously unattended location. The delay to return attention back to a previously attended location appears to reflect the operation of a reactive inhibitory effect on the visual search process (Klein, 2000). IOR is considered to be an important attention-based characteristic of visual search behavior because it could potentially enhance the information-gathering efficiency of searches by biasing attention toward new information in unexplored locations and away from redundant, old information contained in previously searched locations (Klein, 1988).

IOR is evident in individuals across the life span (Clohessy, Posner, Rothbart, \& Vecera, 1992; Faust \& Bolata, 1997). Indeed, studies have demonstrated that IOR is evident in infants (Clohessy et al., 1992), which is consistent with the idea that automatic mechanisms of attention develop early and could precede and possibly facilitate the development of more controlled mechanisms. As such, automatic mechanisms are important to understand in context of developmental disorders, such as ADHD. There has been only one published study of IOR in children with ADHD (Li, Chang \& Lin, 2003). That study compared 11 children who met DSM-IV criteria for the ADHD/C subtype to 12 age-matched comparison children. The study reported slightly smaller IOR effects in the ADHD/C group compared with controls, suggesting that the automatic inhibitory mechanism underlying this attentional process might be weaker in children with ADHD.

To summarize, there is reliable evidence that children with ADHD suffer deficits of intentional inhibitory mechanisms, but little is known about the degree to which automatic inhibitory mechanisms may be impaired in these children. Given the variations in attention and inhibitory problems hypothesized to exist among the diagnostic subtypes of ADHD, it is important to examine whether each subtype is characterized by general inhibitory deficits that involve both intentionally and automatically controlled mechanisms or instead inhibitory deficits that are specific to one particular type of inhibitory mechanism.

The present study compared deficits in intentionally and reflexively controlled inhibition of attention. The children with ADHD were classified as one of two subtypes: ADHD/PI and
ADHD/C. Further, in accordance with recommendations by Lynam (1996) and Nigg (2006), children with ADHD/C who also met criteria for comorbid aggression, oppositional defiant disorder (ODD), or conduct problems were identified and assigned to a separate group (ADHD/C + ODD) to maintain the homogeneity of each subtype group. A deficit of intentionally controlled inhibition was assessed by the countermanding task and a deficit in reflexively controlled inhibition was assessed by the IOR task.

\section{Method}

\section{Participants}

A sample of 50 children with ADHD and 21 comparison children, all ranging in age from 9 to12 years, participated in this study. Demographic information for each of the four diagnostic groups is reported in Table 1. Approximately $73 \%$ of the sample was male (52 of the 71 subjects), and the gender ratio was independent of group, $\chi^{2}(3)=2.5, p=.47$. Analyses of variance (ANOVAs) revealed no significant group differences in age $(p>.13)$, school grade, $(p>.11)$, years of mother's education $(p>.41)$, and child's verbal IQ $(p>.24)$. There was a significant group difference in the matrices subtest of the KBIT, owing to the comparison group scoring higher than the ADHD groups, $F(3,67)=2.9, p=.04$. Approximately $86 \%$ of the children were Caucasian, $11 \%$ were African American, and 3\% were identified as other.

The children with ADHD were recruited from a clinic in the department of psychiatry that specializes in assessing and treating children with ADHD. The children were carefully selected to fulfill the DSM-IV criteria for the ADHD inattentive subtype or ADHD/C subtype, and were relatively free of confounding factors (e.g., psychosis). A three-step diagnostic process was implemented in this study. In the first, potential participants in the study had to have received a diagnosis of ADHD based on the DSM-IV criteria after a thorough assessment at the psychiatric clinic. This diagnosis was made by a team, including a child psychiatrist and another mental health professional. It was based on child and parent interviews, child observations, 
Table 1. Demographic characteristics of groups

\begin{tabular}{lcccc}
\hline \hline & & \multicolumn{3}{c}{ Groups } \\
\cline { 3 - 5 } & Comparison & ADHD/PI & ADHD/C & ADHD/C + ODD \\
\hline$n$ & 21 & 17 & 19 & 14 \\
Male & $67 \%$ & $65 \%$ & $78 \%$ & $86 \%$ \\
Age & $131.2(11.3)$ & $125.1(13.6)$ & $134.8(11.7)$ & $127.6(15)$ \\
Grade & $5.5(1.1)$ & $4.7(1.2)$ & $5.4(1.0)$ & $4.9(1.4)$ \\
Maternal ed. & $16.4(1.7)$ & $15.3(1.9)$ & $15.5(2.2)$ & $15.3(3.3)$ \\
KBIT vocab. & $107.2(11.8)$ & $102.9(13.4)$ & $100.0(10.6)$ & $101.4(9.9)$ \\
KBIT matrices & $120.0(13.3)$ & $109.6(12.4)$ & $109.3(12.4)$ & $108.4(19.1)$ \\
\hline \hline
\end{tabular}

Note: Age, mean $(S D)$ age (months); Grade, mean $(S D)$ grade in school; Maternal ed., mean $(S D)$ education of mother (years); K-BIT vocab., mean IQ on vocabulary subtest; K-BIT matrices, mean IQ on matrices subtest.

and other measures (e.g., Conners' Parent and Teacher Rating Scales). Additional information was obtained when feasible from teachers, referring physicians, and/or psychological test results. Although children with ADHD were diagnosed by a convergence of evidence from multiple informants and multiple measures, the clinic did not employ a standardized set of assessment measures consistent with the systematic criteria necessary for research purposes. Therefore, the clinic diagnosis did not determine inclusion in the study but identified potential children with a clinic diagnosis of ADHD.

In the second step of the diagnostic process, parents of identified children were contacted to request permission for the research team to review the children's files. If parents consented, the clinic files were examined in detail by one of the authors to determine if the child met eligibility criteria for the study. In doing this, additional information was obtained on factors such as children's scores on ADHD rating scales, IQ, medications, additional diagnoses, or reasons for clinical referral. Children were not contacted for participation in this study if it was found that they had a low IQ (i.e., below 80), a hearing impairment or other significant sensory impairment, epilepsy, or were diagnosed with a psychotic disorder, or were prescribed medication that could not be discontinued temporarily for the testing session. Children were not excluded from participation in this study based on the presence of comorbid internalizing or externalizing disorders.

If the above criteria were met, then the parent of the child with ADHD was contacted and invited to participate in this study. The third step of the diagnostic process was to collect standardized interview and behavior rating scale information to confirm the ADHD diagnosis. A semistructured interview, similar to the Children's Interview for Psychiatric Syndromes-Parent Version (P-ChIPS; Weller, Weller, Rooney, \& Fristad, 1999), but only consisting of verbatim $D S M-I V$ criteria for ADHD and ODD, was conducted with the parent. In the interview, the parent was asked whether each diagnostic criterion was true of his/her child, and, if so, the parent was asked to give behavioral examples. If a behavioral symptom was deemed to be characteristic of the child, the parent then was asked whether that behavior seemed inappropriate for the child's age and whether it impaired the child's functioning academically and socially. A diagnostic criterion was only considered to be endorsed if the parent indicated the behavior was age inappropriate and impairing. This interview procedure has been used successfully in previous studies, with interrater reliabilities for the number of ADHD symptoms endorsed by the parent to be above 95\% (e.g., Lorch et al., 1999).

In addition to the information from the structured psychiatric interview, parents completed the Child Behavior Checklist (CBCL; Achenbach, 1991) and the Conners Parent Rating Scales (CPRS-R:S; Conners, 1990). The data for children whose parental interviews supported a diagnosis of $\mathrm{ADHD} / \mathrm{C}$ or inattentive type were retained for analysis in this study.

Children with ADHD were assigned to one of the three subgroups under investigation (ADHD/ $\mathrm{C}, \mathrm{ADHD} / \mathrm{PI}, \mathrm{ADHD} / \mathrm{C}+\mathrm{ODD}$ ) based on the history obtained from the psychiatric chart review 
as well as the more systematic data obtained from the structured interview and the CBCL and CPRS-R:S. To be placed in the ADHD/C group, children must have met criteria for this diagnosis on the structured interview, have $T$ scores above 60 on the Conners Hyperactivity Scale and the ADHD Index, and have $T$ scores below 60 on the CBCL Aggression and Delinquency Scales. To be included in the ADHD/C + ODD group, the child must have met criteria for an ADHD/ $\mathrm{C}$ diagnosis, criteria for an ODD diagnosis, and also have a CBCL aggression or delinquency $T$ score above 60. In forming the ADHD/PI group, recommendations made by Milich et al. (2001) were followed to ensure that this group did not include subthreshold ADHD/C children. Thus, the children in the ADHD/PI group had to meet criteria for attention problems on the structured interview and have three or fewer symptoms on the hyperactive/impulsive dimension. In addition, the children had to have $T$ scores above 60 on the Conners Cognitive Problems/Inattention Scale, less than 60 on the Hyperactivity Scale, and less than 60 on the CBCL Aggression and Delinquency Scales. Table 2 summarizes the mean scores on these diagnostic measures for the three ADHD groups, documenting that the groups differed significantly on the relevant diagnostic indicators.

The comparison group of children without ADHD was recruited through newspaper advertisements, posted advertisements in the community, and by word of mouth. They were screened during a recruitment phone call in which the parents were asked if their child had ever been referred for any behavioral or learning problems. The comparison children were not required to be symptom free but instead the children in the comparison group had to have less than three symptoms on each of the symptom dimensions (i.e., inattentive, hyperactive/impulsive, and oppositional defiant disorder) from the structured psychiatric interview. In addition, the children must have had $T$ scores of less than 60 on all of the rating scales. As indicated in Table 2, these children were significantly less symptomatic than the children with ADHD in terms of the $D S M-I V$ criteria for inattentive symptoms and hyperactivity/impulsivity symptoms and did not meet diagnostic criteria for any subtype of ADHD. In addition, the children in the compar- ison group had to have $T$ scores below 60 on all of the relevant rating scales. Thus, the diagnostic interview and rating scale data successfully differentiated between the comparison children and the three ADHD groups.

Among the children with ADHD, 36 children were being maintained on psychostimulant medication for ADHD and the other 14 children were not taking any prescribed medication. No child received any psychostimulant medication on the day of the study until the session was completed. This provided a sufficient time period ( $~ 24 \mathrm{hr}$ ) for clearance of any medication administered on the day of the session. The study was approved by the university's institutional review board. All children received two small toys and $\$ 30.00$ for their participation in the study, which was part of a larger project.

\section{Procedure}

The study took place at the Behavioral Pharmacology and Neurocognition Research Laboratory in the university's Department of Psychology. All children were tested individually. Testing occurred on a nonschool day between 9 a.m. and 5 p.m. Upon arrival at the lab, the child and parent were greeted by two experimenters who described the general details of the study and the basic testing procedures. Written consent then was obtained from the parent and verbal assent was obtained from the child. Next, one of the experimenters accompanied the parent to an interview room to complete the semistructured interview and questionnaires. The other experimenter accompanied the child to a nearby room to complete the testing. The experimenter administered the K-BIT followed by the countermanding task and the IOR task. The countermanding and IOR tasks were chosen because they were similar in their response requirements (i.e., detecting targets presented along a horizontal plane), but differed in the nature of the inhibitory mechanism implicated (intentional vs. automatic).

The administration of these tasks was part of a larger testing battery that contained neuropsychological tests and other measures of cognitive functioning. Prior to each test, the experimenter provided the task instructions and the children performed a brief 2- to 3-min familiarization test on each task to ensure that the child understood 
Table 2. Diagnostic indicators of groups

\begin{tabular}{lcccc}
\hline \hline & & \multicolumn{3}{c}{ Groups } \\
\cline { 3 - 5 } & Comparison & ADHD/PI & ADHD/C & ADHD/C + ODD \\
\hline DSM & & & & \\
$\quad$ Hyperactive & $0.4(0.7)_{\mathrm{a}}$ & $1.5(1.5)_{\mathrm{a}}$ & $4.4(1.2)_{\mathrm{b}}$ & $6.9(2.7)_{\mathrm{c}}$ \\
$\quad$ Attention & $0.5(1.1)_{\mathrm{a}}$ & $6.2(2.6)_{\mathrm{b}}$ & $6.5(2.1)_{\mathrm{b}}$ & $7.9(1.6)_{\mathrm{b}}$ \\
$\quad$ ODD & $0.2(0.4)_{\mathrm{a}}$ & $1.1(1.3)_{\mathrm{a}}$ & $2.3(1.4)_{\mathrm{b}}$ & $4.9(2.2)_{\mathrm{c}}$ \\
CPRS & & & & \\
$\quad$ Hyperactive & $47.8(5.1)_{\mathrm{a}}$ & $53.1(11.6)_{\mathrm{a}}$ & $74.2(9.6)_{\mathrm{b}}$ & $81.1(9.8)_{\mathrm{b}}$ \\
ADHD & $44.7(3.4)_{\mathrm{a}}$ & $68.5(8.5)_{\mathrm{b}}$ & $74.6(6.5)_{\mathrm{c}}$ & $75.2(7.9)_{\mathrm{c}}$ \\
$\quad$ Cognitive & $45.1(3.8)_{\mathrm{a}}$ & $71.5(9.3)_{\mathrm{b}}$ & $72.9(7.4)_{\mathrm{b}}$ & $76.2(8.7)_{\mathrm{b}}$ \\
CBCL & & & & \\
$\quad$ Aggression & $51.1(3.9)_{\mathrm{a}}$ & $54.4(5.9)_{\mathrm{a}}$ & $55.4(10.4)_{\mathrm{a}}$ & $70.8(9.3)_{\mathrm{b}}$ \\
Delinquency & $51.4(2.8)_{\mathrm{a}}$ & $53.2(5.7)_{\mathrm{a}}$ & $53.6(4.2)_{\mathrm{a}}$ & $65.3(8.8)_{\mathrm{b}}$ \\
\hline \hline
\end{tabular}

Note: DSM, mean symptom counts from DSM interview for hyperactivity, attentional problems, and oppositional defiant disorder (ODD); CPRS, mean ratings on Conners Parent Rating Scales for hyperactivity, ADHD index, and cognitive problems/inattention; CBCL, mean scale ratings on Child Behavior Checklist for aggression and delinquency. Group differences among DSM, CPRS, and CBCL indicators were tested by Tukey's honestly significant difference tests based on MS error terms from the one-way ANOVAs. Significant group differences are denoted by subscript letters. Groups with the same subscripts indicate nonsignificant differences.

the task requirements. Children were given a 15min break between each testing component. At the conclusion of the session, the child and parent were debriefed and paid for their participation.

Countermanding task. This task, along with the IOR task, was operated using E-prime experiment generation software (Schnieder, Eschman, \& Zuccolotto, 2002) and performed on a personal computer. A chin rest was used to stabilize head movement and maintain a constant eye-to-screen distance of $73.7 \mathrm{~cm}$. The countermanding task measured children's ability to intentionally inhibit the allocation of attention to stimuli that are to be ignored. The task is similar to the stop-signal task except that the behavioral response examined is an eye movement (Logan \& Irwin, 2000). The task requires participants to execute quick saccades to go signals, but to inhibit these saccades on occasion when auditory stop signals also occur. The go signals were circles that were $8 \mathrm{~mm}$ in diameter and were presented one at a time. Each trial began with a $1000 \mathrm{~ms}$ presentation of a fixation stimulus (a plus sign) in the middle of the computer display. This served to fixate attention and to indicate the start of a trial. Once the fixation disappeared, a circle was displayed for $1000 \mathrm{~ms}$ in one of four horizontal positions with respect to the fixation: far right $(12 \mathrm{~cm})$, middle right $(6.5 \mathrm{~cm})$, far left $(12 \mathrm{~cm})$, and middle left $(6.5 \mathrm{~cm})$. Following the circle, the screen was blank for $1500 \mathrm{~ms}$ before the start of the next trial. The circle was the go signal. Its sudden appearance elicits an exogenous (i.e., a reflexive) saccade, but the children were also instructed to look at the circle as quickly as possible when it appears. On some trials, a stop signal also was presented. The stop signal was a $500-\mathrm{ms} 900-\mathrm{Hz}$ tone generated by the computer at a comfortable listening level. The children were instructed not to look at the circle (i.e., inhibit their eye movement) when a stop signal was presented. Thus, the children were required to intentionally countermand the saccade to the circle when they heard the stop signal sound.

A test consisted of 128 trials in which the four circle positions were presented an equal number of times (32 times). Stop signals occurred on 32 trials (i.e., $25 \%$ of the time). Stop-signal presentations occurred equally among circle positions and were presented eight times at each of four delays with respect to the onset of the circle presentation. These stimulus onset asynchronies (SOAs) were $0,50,100$, and $150 \mathrm{~ms}$. Trial order with respect to circle position, occurrence of stop signal, and stop signal SOA was random. A test required about $8 \mathrm{~min}$ to complete. Eye movements were recorded using a Model 504 Eye Tracking System (Applied Science Laboratory, 
Boston). Eye locations were sampled at $60 \mathrm{~Hz}$ and given an $X / Y$ coordinate. These coordinates were used to define fixations and saccades.

IOR task. The IOR task measured an automatically occurring or reflexive inhibitory mechanism that subserves selective attention. The task required children to quickly detect the appearance of a simple visual target. A trial began with a 500-ms presentation of a fixation stimulus (a plus sign) in the middle of the screen that fixated attention and indicated the start of a trial. After a 500-ms delay (blank screen), three $4-\mathrm{cm}^{2}$ white box outlines were presented on a black background in the center of the display. The boxes were aligned horizontally with a 7-cm distance between each peripheral box and the center box. Following a 500-ms interval, a cue was displayed as a brief (20-ms) increase in brightness of one of the peripheral boxes. This cue was followed $10 \mathrm{~ms}$ later by a $20-\mathrm{ms}$ brightness increase of the center box. This served to disengage attention from the cue and redirect it back to the center of the display (Briand, Larrison, \& Sereno, 2000). A target then appeared inside one of the peripheral boxes. The target was a white star $(2-\mathrm{cm}$ diameter) that was displayed for $1000 \mathrm{~ms}$ or was terminated once a response was made. The children were required to press the forward slash key (/) of the keyboard as soon as they detected the target in either of the peripheral boxes. Targets were presented at one of three cue-target SOAs (450, 900, and $1200 \mathrm{~ms})$. Trials were separated by a $500-m s$ blank display, intertrial interval.

Trials represented one of three conditions: same cue-target condition, control condition, and catch condition. The same cue-target condition comprised trials in which the cue and target appeared at the same location. The control condition was comprised of trials in which the cue and target appeared at different locations. The catch condition was comprised of "catch" trials in which a cue was presented but no target followed, and therefore, no response was required. Catch trials are commonly used in IOR tasks to prevent anticipatory responding (i.e., Lupianez, Milliken, Solano, Weaver \& Tipper, 2001). These trials also serve as an instruction comprehension check by allowing the examiner to verify that children responded only when targets were displayed.
A test consisted of 150 trials comprising an equal number of same cue-target and control trials (60 trials each). The remaining 30 trials were catch trials. For the same cue-target and control conditions, the three cue-target SOAs were presented an equal number of times (20 trials in each condition). Research shows that maximal IOR effects occur at SOAs ranging from 400 to $600 \mathrm{~ms}$ (Klein, 2000; Lupianez et al., 2001; Lupianez, Milan, Tornay, Madrid, \& Tudela, 1997; Posner \& Cohen, 1984). This study included a 1200-ms cue-target SOA that extended beyond this range to observe the duration of the IOR effect. Trials were presented in a random order with respect to condition and cue-target SOA. A test required approximately $8 \mathrm{~min}$ to complete.

\section{Criterion measures}

Countermanding task. The principal measure of inhibitory control on the countermanding task was the SSRT. SSRT is the time needed to inhibit the saccade to the circle once the stop signal occurs and represents the time difference between the onset of the stop signal and the point at which the inhibitory process is completed. The method for calculating SSRT was based on the child's probability of inhibiting saccades to stop signals and the distribution of RTs to go-signal trials. The calculations are explained in detail elsewhere (e.g., Logan, 1994), but the general logic of the method is outlined here.

The SSRT estimate is based on a method of determining how long the stop signal can be delayed after the go signal before the child can no longer inhibit the saccade. The SSRT is estimated by using the distribution of observable saccadic RTs on go-signal trials (RTgo) and the probability of inhibiting saccades on stop-signal trials as a function of the stop-signal delay (SOA). The probability of inhibiting a saccade at each stop-signal delay was determined by the number of stop-signal trials at each SOA in which the child successfully inhibited the saccade. Any saccade toward the target that traveled at least one half of the distance before being countermanded was considered to be an inhibition failure (Abroms, Gottlob, $\&$ Fillmore, 2006). One of the assumptions of this calculation is that inhibiting to the stop signals at the various SOAs chosen (i.e., 0, 50, 100, and $150 \mathrm{~ms}$ ) should of moderate difficulty, avoiding 
ceiling effects in which participants are able to successfully inhibit most of the time (probability of inhibition $\approx 1.0$ ) and avoiding floor effects in which participants fail to successfully inhibit most of the time (probability of inhibition $\approx 0$ ). The average probability of inhibiting in the study was 0.56 , which did not significantly differ from a 0.50 midlevel of probability $(p>.05)$.

RTgo referred to the time to complete a saccade to the circle on trials in which no stop signal sounded and was measured as the time lapse in milliseconds between the onset of a circle presentation and the onset of the resulting fixation at the target location. A mean RTgo score averaged over all go trials was calculated for each child.

The countermanding task also measured the variability of a child's mean saccadic RT by the standard deviation of the child's RTs (RTSD) on the go-signal trials. Previous research using the stop-signal task has found that ADHD is characterized by increased variability in button-press reaction times to go signals, possibly reflecting inconsistent attention to the task from trial to trial (Schachar et al., 1995; Schachar \& Tannock, 1995). No research has examined the possibility that this increased variability in button-press RT might also generalize to eye movement RT as measured by the countermanding task. Finally, the countermanding task also measured omission errors of saccades on go signal. An omission error occurred when a child failed to make a saccade to a target on one of the 96 go-signal trials.

Group effects on SSRT, mean RTgo, RTSD scores, and omission errors were analyzed individually by one-way ANOVAs. For each measure, three planned comparison $t$ tests were performed that compared each ADHD group to the comparison group. Post hoc comparisons among ADHD groups were examined by Tukey honestly significant difference tests controlling for experiment-wise error rates. Data were missing for six participants because of problems tracking the participants' eyes during the test. Data for three other participants were excluded from analyses on this task because they did not follow task instructions. Together, these nine participants represented all four groups: comparison $(n=1)$, ADHD/PI $(n=$ $3), \mathrm{ADHD} / \mathrm{C}(n=2)$, and $\mathrm{ADHD} / \mathrm{C}+\mathrm{ODD}(n=3)$.

IOR task. Reaction time to detect a target was the principal performance measure and was re- corded as milliseconds to respond after the onset of a target. For each participant, a mean RT score was calculated for the same cue-target condition and for the control condition at each SOA for a test. Responses with RTs less than $100 \mathrm{~ms}$ or greater than $1000 \mathrm{~ms}$ were excluded. These outliers were infrequent, and occurred on less than an average of $1 \%$ of the trials in either cue-target condition during a test. The task also records omission and commission errors, but these errors were too infrequent for analysis.

The IOR effect in a group is evidenced by a slower RT on same cue-target trials versus control trials. Group differences in IOR were examined by a Four Group (ADHD/PI, ADHD/C, ADHD/C + ODD, Comparison) $\times 2$ Trial Condition (same cue-target vs. control) $\times 3$ SOA $(450,900$, and $1200 \mathrm{~ms}$ ) mixed model ANOVA of RT. Any diminished IOR effect in the ADHD groups versus the comparison group was indicated by an interaction involving the trial condition and group.

$I Q$ as a covariate. All analyses for both tasks were conducted with and without participants' verbal and matrices IQ scores as covariates. Results of analyses with the IQ scores as covariates did not differ from analyses without the covariates. Therefore, analyses are reported without IQ scores as covariates.

\section{Results}

\section{Countermanding task}

There was a significant group effect for SSRT scores, $F(3,58)=4.1, p=.01$. As shown in the left panel of Figure 1, all three ADHD groups had longer SSRT scores than the comparison group. This was confirmed by planned comparisons of each ADHD group to the comparison group ( $p \mathrm{~s}<.02, d \mathrm{~s}>0.9$ ), with ADHD groups being slower to inhibit saccades by at least $110 \mathrm{~ms}$ to as much as $160 \mathrm{~ms}$. Among the three ADHD groups (ADHD/PI, ADHD/C, and ADHD/C + ODD), post hoc comparison tests revealed no significant differences in SSRT $(p s>.80)$.

There were no significant group differences among the children's mean RTgo scores, $F$ (3, $58)=0.3, p=.83$, as shown in the right panel of Figure 1. The overall mean RTgo score for the entire sample was $380.4 \mathrm{~ms}(S D=65.2)$. 


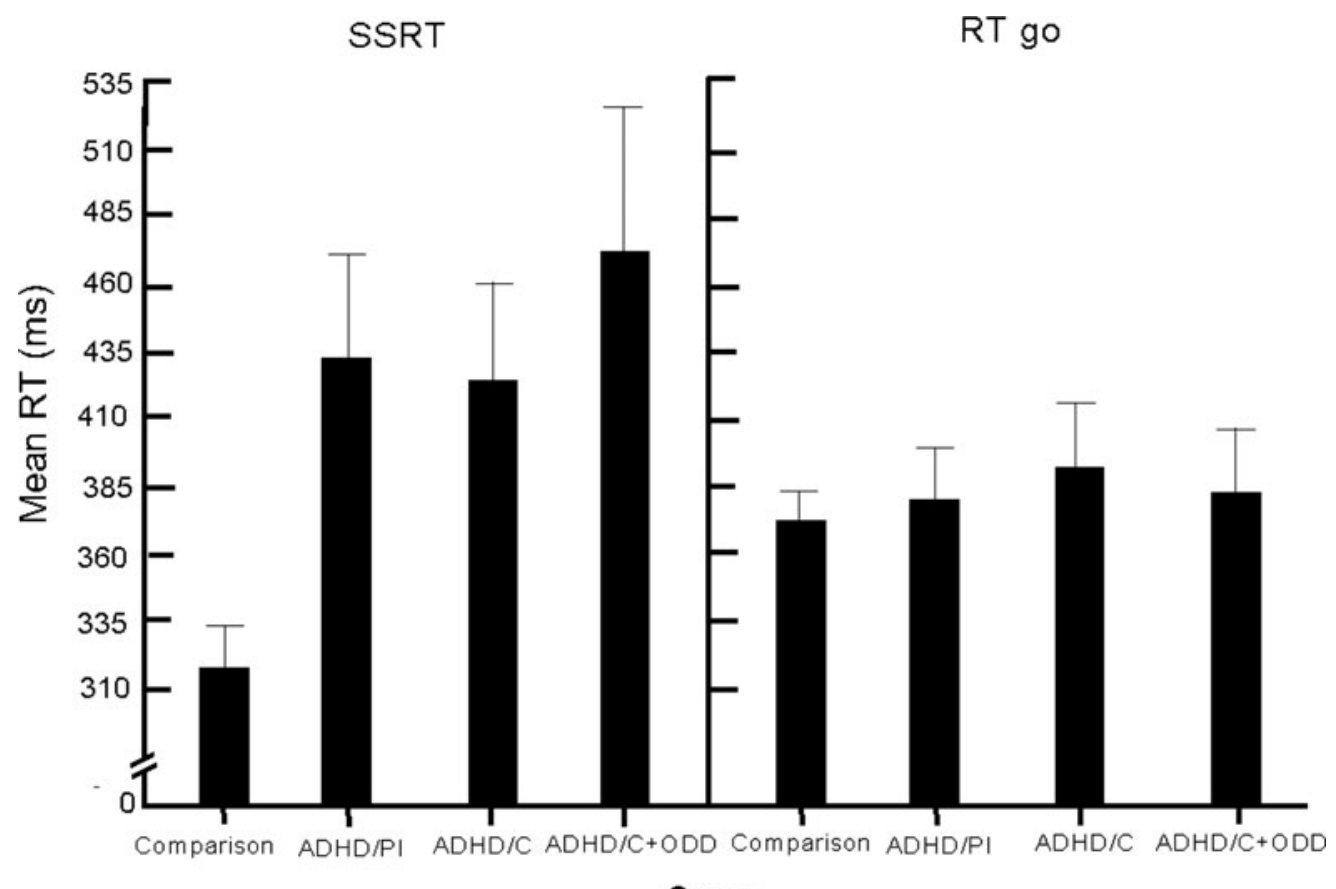

Group

Figure 1. Mean stop-signal reaction times (SSRTs) and mean RTs on go signals (RTgo) scores (ms) on the countermanding task for each group. Capped vertical lines indicate standard error of the mean.

A significant difference among the groups was obtained for the standard deviations of the children's mean RTgo scores (RTSD), $F$ $(3,58)=3.6, p=.02$. As shown in Figure 2, all three ADHD groups displayed significantly more variable reaction times than those of the comparison group ( $p \mathrm{~s}<.02, d \mathrm{~s}>0.8$ ). Among the three ADHD groups (ADHD/PI, $\mathrm{ADHD} / \mathrm{C}$, and ADHD/C + ODD), post hoc comparison tests revealed no significant differences in RTSD scores ( $p$ s $>$.97).

Finally, omission errors occurred infrequently and did not differ among groups, $F(3,58)=1.0$, $p=.38$. On average, omission errors occurred on only $10 \%$ of trials for the entire sample.

\section{IOR task}

A 4 (Group) $\times 2$ (Trial Condition $) \times 3(\mathrm{SOA})$ mixed-model ANOVA of RT obtained significant main effects of group, $F(3,67)=4.3, p$ $=.01$, and cue, $F(1,67)=14.2, p<.01$, as well as a significant Group $\times$ Cue interaction, $F(3,67)=5.4, p<.01$, and significant three-way interaction, $F(6,134)=2.7, p=$
.02. Figure 3 plots the mean RT at each SOA for each cue condition. The figure shows that RTs are generally slower in the ADHD groups compared with those in the comparison group. The figure also illustrates the IOR effect in the comparison group as evident by the consistently slower RTs in the same cue-target condition compared with the control (i.e., different cue-target) condition. Those in the ADHD/PI group showed the IOR effect at the shortest and longest SOA but not at the intermediate SOA. By contrast, no appreciable IOR effect was evident in the ADHD/C and ADHD/C + ODD groups. This was confirmed in each group by $t$ tests that compared the mean RT in each cue condition averaged over SOA. A significant IOR effect (i.e., same cue-target RT $>$ different cue-target) was demonstrated in the comparison group, $t(20)=7.1, p<.01, d=1.5$, and in the ADHD/PI group, $t(16)=2.5, p=$ $.02, d=0.6$. By contrast, no significant IOR effect was evident in the ADHD/C and ADHD/C + ODD groups $(p s>.59)$. Figure 4 illustrates the magnitude of the IOR effect in each group expressed as the mean RT difference between 


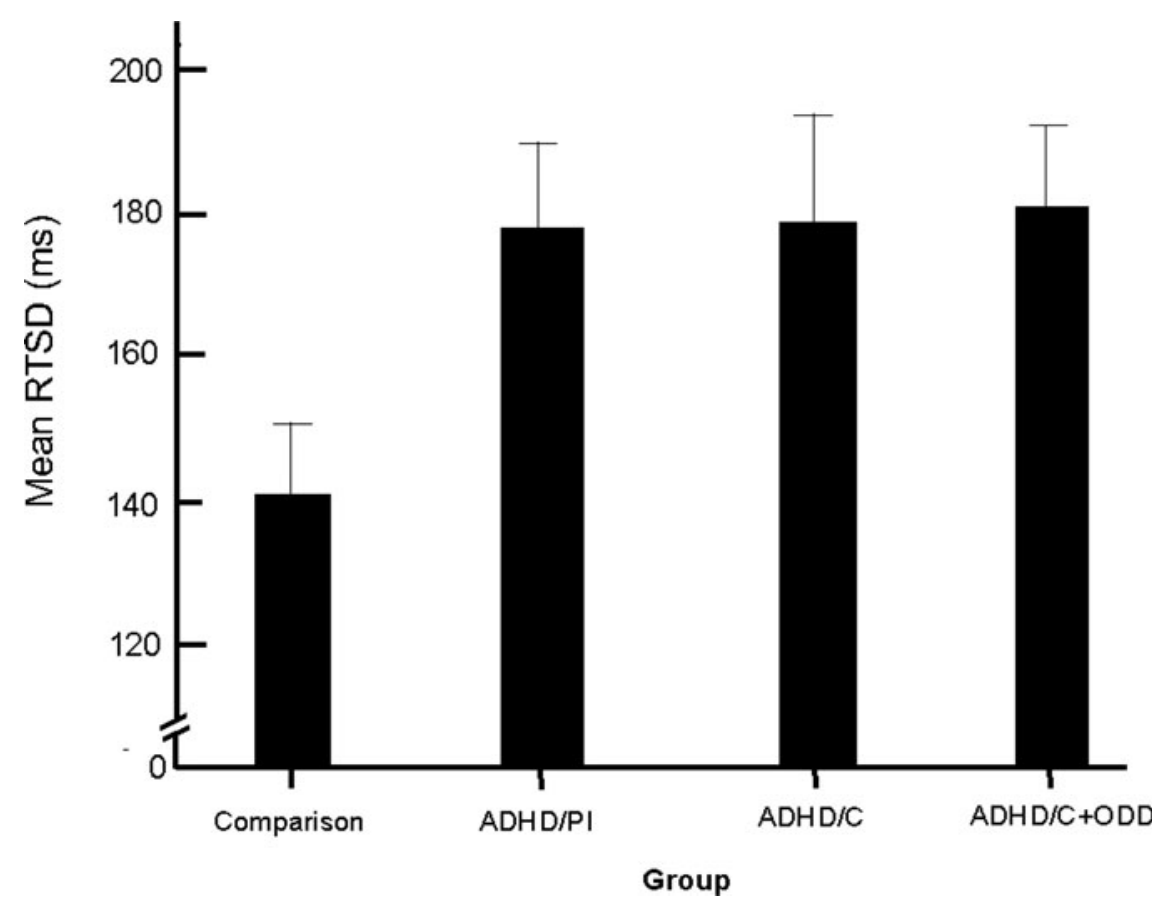

Figure 2. Standard deviation of reaction times over trials (RTSD) on the countermanding task, averaged for each group. Capped vertical lines indicate standard error of the mean.

the same and different cue-target conditions. The figure shows that the comparison group displayed the greatest degree of IOR followed by the ADHD/PI. No appreciable IOR effect was evident in $\mathrm{ADHD} / \mathrm{C}$ and $\mathrm{ADHD} / \mathrm{C}+$ ODD groups. A one-way ANOVA of these RT difference scores confirmed a significant group difference, $F(3,67)=5.4, p<.01$, and multiple comparison tests based on the ANOVA supported the observations in Figure 4. There was no significant difference in IOR effect between the ADHD/C and ADHD/C + ODD groups $(p=.45)$. Compared with the combination of $\mathrm{ADHD} / \mathrm{C}$ and $\mathrm{ADHD} / \mathrm{C}+$ ODD group, significantly greater IOR was displayed by those in the comparison group, $F(1$, $67)=14.7, p<.01, d=1.1$, and by those in the ADHD/PI group, $F(1,67)=3.1, p=.04, d=$ 0.4 . The difference in IOR effect between the ADHD/PI and comparison group did not attain statistical significance $(p=.10)$.

\section{Discussion}

The present study compared deficits in intentionally and reflexively controlled inhibition of at- tention among subtypes of children with ADHD. The countermanding task assessed intentionally controlled inhibition, whereas the IOR task assessed reflexively controlled inhibition. Although deficits among children with ADHD were found both for intentionally controlled and reflexively controlled inhibition of attention, the ADHD/PI group exhibited a different pattern of impairment than the other two subtypes. With respect to reflexively controlled inhibition, children in the ADHD/C and ADHD/C + ODD groups showed substantial impairment as evidenced by a complete absence of reflexive inhibition. Children in the ADHD/PI group also displayed impaired reflexive inhibition, although the impairment was somewhat less. On the countermanding task, children in the three ADHD groups required more time to intentionally inhibit responses (i.e., longer SSRTs) than did the comparison children, but the magnitude of impairment did not differ significantly among the three ADHD subtypes.

Deficits in IOR have been observed in disorders other than ADHD that are characterized by attentional impairments, including schizophrenic patients (Gouzoulis-Mayfrant, Arnold, \& 


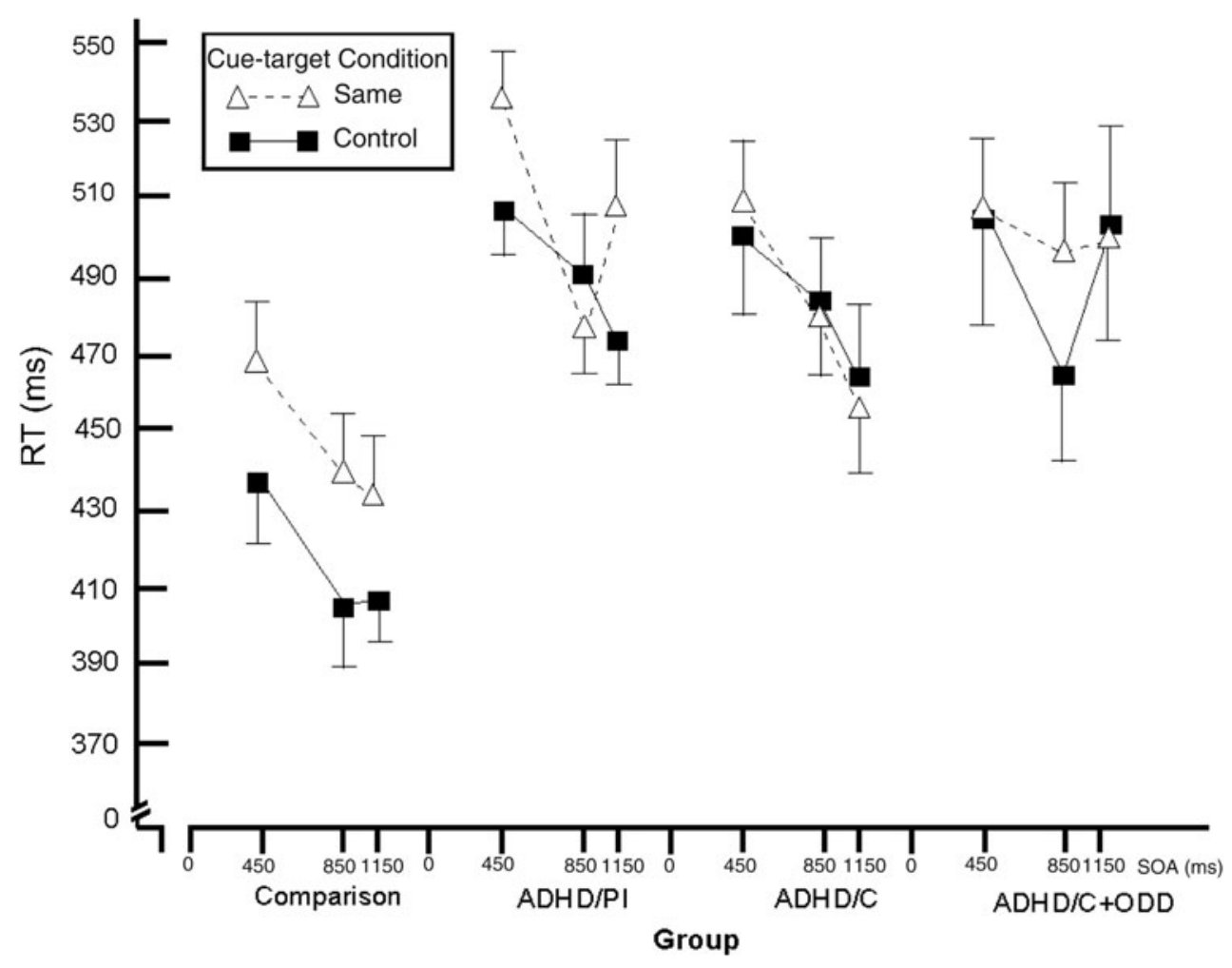

Figure 3. Mean reaction time (ms) for target detection as a function of group, cue condition, and stimulus onset asynchronies. Capped vertical lines represent standard error of the mean.

Heekeren, 2006) and those with Huntington disease (Fielding et al., 2006). In addition, alcohol, which is known to impair selective attention, has been shown to reduce IOR in healthy adult social drinkers (Abroms \& Fillmore, 2004). With regard to ADHD, only one previous study reported testing IOR in children with ADHD (Li et al., 2003). That study examined only the combined subtype and found those children to display a reduced IOR effect compared with controls. However, what is particularly noteworthy about the present study is that it demonstrates a complete absence of the IOR effect in both the ADHD/C and ADHD/ $\mathrm{C}+$ ODD subtypes, suggesting that children in these two subtypes are markedly deficient in their ability to inhibit attention reflexively.

These findings are consistent with Barkley's (1997) argument that inhibitory deficits underlie most, if not all impairments, exhibited by children with ADHD, including their attentional problems. In particular, the results are consistent with the idea that some of the attentional prob- lems associated with ADHD/C stem from an inability to inhibit the draw of attention toward irrelevant or distracting stimuli. Such a conclusion is consistent with results from a series of studies by Lorch, Berthiaume, Milich, and van den Broek (2007) when studying the relation between attention and story comprehension among children with ADHD. In addition, the fact that children with ADHD show decreased distractibility when treated with stimulant medication is consistent with the finding that reduced IOR among adults with a history of stimulant abuse can be restored by the administration of the psychostimulant drug, $d$-amphetamine (Fillmore, Rush, \& Abroms, 2005).

In contrast to the results for the $\mathrm{ADHD} / \mathrm{C}$ and $\mathrm{ADHD} / \mathrm{C}+\mathrm{ODD}$ groups, the ADHD/PI group demonstrated a significant IOR effect, although an examination of the means suggests that the magnitude of that effect was only about $50 \%$ of that displayed by the comparison group. The different pattern exhibited by the ADHD/PI group is noteworthy for at least two reasons. First, this is 


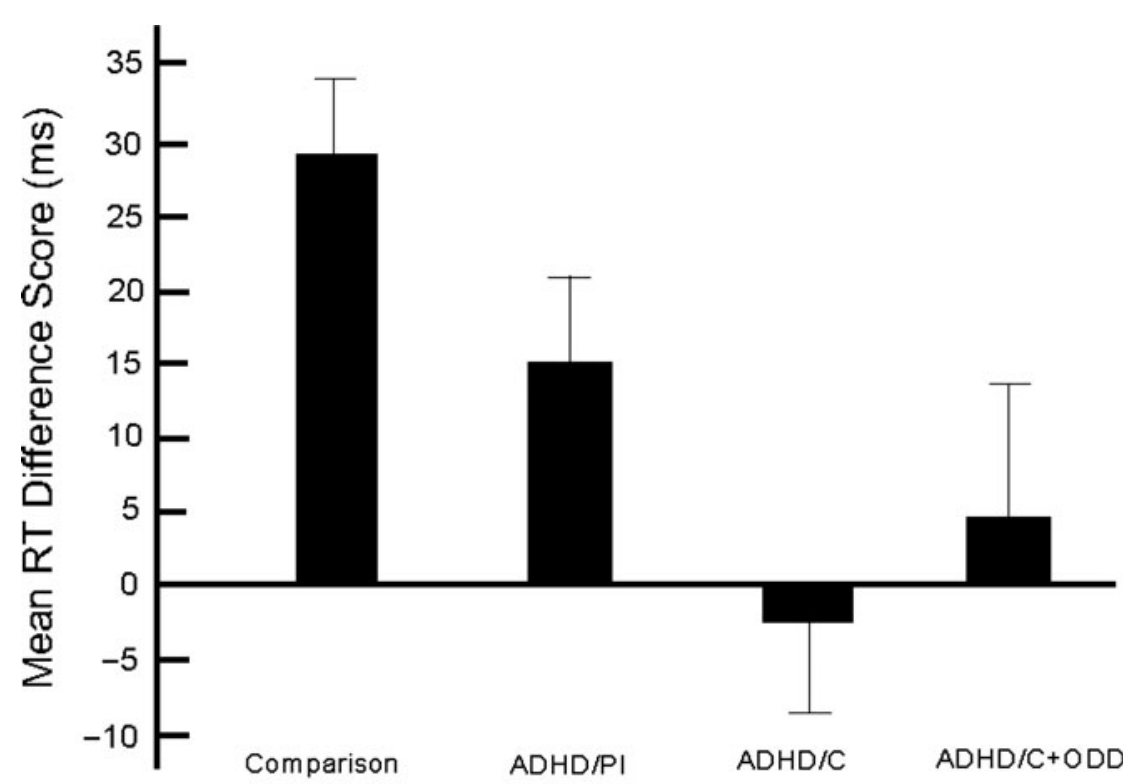

\title{
Group
}

\begin{abstract}
Figure 4. Mean magnitude of the inhibition of return (IOR) effect expressed as the RT difference (ms) between target detection in the same cue-target condition versus the control cue-target condition, averaged over the three stimulus onset asynchronies. Positive difference scores indicate longer RTs in the same cue-target condition versus the control cue-target condition and thus represent larger IOR effects. A zero difference indicates no IOR effect (i.e., same cue-target RT = control cue-target RT).
\end{abstract}

one of the first studies to document that a basic inhibitory process that aids selective attention may be present in the ADHD/PI group but absent in the other subtypes (see also, O'Driscoll et al., 2005). Second, although attentional problems are an integral component of the diagnosis for all three subtypes, the pattern of IOR effects suggests that the mechanisms underlying the attention problems may differ across the subtypes. Thus, distraction by external stimuli may be less central to the attention problems of children in the ADHD/PI subtype than for children in the other subtypes. This conclusion is consistent with clinical observations of children with the ADHD/PI subtype. Rather than being highly distracted, these children typically are viewed as being "lost in space," "daydreaming," and having "sluggish cognitive tempo" (Milich et al., 2001). The extent to which common observations, such as sluggish cognitive tempo, might represent specific impairments of selective attention is of current interest among researchers (e.g., Huang-Pollock, Nigg, \& Carr, 2005). Unfortunately, as Milich et al. note, few studies have ex- amined systematically the nature of the attention problems across carefully defined subtypes.

It is also worthwhile considering the findings regarding the IOR effects from a developmental perspective. Given that studies find IOR to be a robust phenomenon, evident in young children and infants (Clohessy et al., 1992; Klein, 2000), it is somewhat surprising to find that the effect was completely absent in two of the three subtypes of ADHD examined in the present study (i.e., ADHD/C and ADHD/C + ODD). The majority of children in the study were 10 to 11 years old, an age in which IOR effects should be robust. Indeed, those in the comparison group displayed a magnitude of IOR that was comparable to that observed in healthy adults (Abroms \& Fillmore, 2004), suggesting this reflexive inhibitory mechanism had fully matured in these children. Nonetheless, despite being of similar age, those in the ADHD/C and $\mathrm{ADHD} / \mathrm{C}+\mathrm{ODD}$ groups displayed no evidence of an IOR effect. The findings raise important questions about the extent to which the development of this reflexive mechanism might be 
limited or delayed in these children. With regard to the ADHD/PI subtype, a similar question arises about whether these children are displaying a weaker IOR effect that might strengthen as they get older. Answers to these questions will require longitudinal examination of children with ADHD across a wider age range than that present in the current study.

The present study also provides new information regarding deficits of intentionally controlled inhibition in children with ADHD. Although problems in intentionally controlled inhibition have been documented extensively for the combined type of ADHD using manual stop-signal tasks (Tannock, 1998), the current findings indicate that deficits of intentionally controlled inhibition in this subtype also are evident in the specific control of eye movements. Moreover, the present study shows that this inhibitory deficit is not specific to the combined subtype but also is observed in ADHD/PI and ADHD/C + ODD subtypes as well. These findings raise the intriguing question of why the subtypes differ in their degree of deficit in automatic inhibitory processes but not in intentionally controlled inhibition. One explanation is that the automatic and intentional inhibitory mechanisms reflect two relatively independent processes so that it is possible to be deficient in one but not the other. A related explanation is that the ADHD/C and ADHD/C + ODD groups have such generalized inhibitory deficits that difficulties are exhibited on both reflexive and intentional inhibitory tasks. In contrast, inhibitory deficits in the ADHD/PI group may be more narrow and only are apparently when children need to inhibit responses intentionally.

It is also important to consider the findings in terms of their potential interdependence during cognitive development. It has been suggested that reflexive mechanisms of attention emerge early in the course of development and could facilitate the development of more controlled inhibitory mechanisms of attention that are assumed to develop later (Aksan \& Kochanska, 2004; Luna et al., 2004). This raises the possibility that the efficient operation of reflexive inhibitory mechanisms, such as those underlying the IOR effects, might be necessary for the development of efficient intentional control of inhibition, such as in the ability to quickly countermand a saccade. However, the results for the ADHD/PI group are not consistent with this interpretation, because this group showed a significant IOR effect but still was impaired in their level of intentionally controlled inhibition. This suggests that the reflexive inhibitory mechanism might be necessary but not sufficient to facilitate intentional inhibitory processes. Alternatively, as suggested above, reflexive and intentional inhibitory processes may be independent. A third possibility concerns the fact that the IOR effect in the ADHD/PI group was smaller compared with the effect displayed by the comparison children. It may be that the automatic inhibitory mechanism needs to be fully developed for it to facilitate intentionally controlled inhibition. Additional studies examining the developmental course of automatic and intentional inhibitory control among both typical and atrisk populations are needed to resolve this issue.

Finally, in addition to the specific measures of inhibitory mechanisms, other measures from the countermanding and IOR tasks also indicated the presence of attentional problems among the subtypes. Relative to comparison children, all three groups showed greater variability of RTs on the countermanding task and slower RTs on the IOR task. Studies using the stop-signal task also have found greater variability in go-signal RTs in children with ADHD, which could reflect inconsistent attention to the task from trial to trial (e.g., Schachar et al., 1995). Saccadic responses on the countermanding task replicate the general pattern of effects evident with manual stop-signal studies of children with ADHD (Tannock, 1998). In fact, Castellanos and Tannock (2002) have conceptualized response variability as a defining feature of ADHD, and the current results are consistent with this conceptualization. In addition to increased variability on the countermanding task, all three ADHD groups showed slower overall reaction times on the IOR task than did the comparison group. Slower reaction times in simple detection tasks have been reported before in children with ADHD (Leth-Steensen, Elbaz, \& Douglas, 2000). Taken together, the results of the present study suggest that difficulties in sustaining attention are common to all three ADHD subtypes.

One limitation of the study that needs to be acknowledged concerns the diagnostic procedures employed. Specifically, it was not possible 
to confirm the diagnoses with systematic teacher ratings. However, we believe this limitation was offset by the use of a clinic referred sample that received an extensive psychiatric workup before the diagnosis was made, and that the diagnosis was then confirmed with a structured diagnostic interview and validated parent rating scales. Further, the recommendations of Milich et al. (2001) and others (e.g., Nigg, 2006) were followed to ensure that the inattentive group did not include children who actually may have had a subthreshold version of the combined type. Thus, we believe that we have identified valid and distinct subtypes of the disorder.

In conclusion, the present research contributes new information regarding the nature of the inhibitory impairments that have become widely documented in studies of children with ADHD. By distinguishing between reflexively

\section{References}

Abroms, B. D., \& Fillmore, M. T. (2004). Alcohol-induced impairment of inhibitory mechanisms involved in visual search. Experimental and Clinical Psychopharmacology, 12, 243-250.

Abroms, B. D., Gottlob, L., \& Fillmore, M. T. (2006). Alcohol effects on inhibitory control of attention: Distinguishing between intentional and automatic mechanisms. Psychopharmacology (Berlin), 188, 324-334.

Achenbach, T. M. (1991). Manual for the Child Behavior Checklist/4-18 and 1991 profile. Burlington, VT: University of Vermont, Department of Psychiatry.

Aksan, N., \& Kochanska, G. (2004). Links between systems of inhibition from infancy to preschool years. Child Development, 75, 1477-1490.

American Psychiatric Association. (1994). Diagnostic and statistical manual of mental disorders (4th ed.). Washington, DC: Author.

Barkley, R. A. (1997). Behavioral inhibition, sustained attention, and executive functions: Constructing a unifying theory of ADHD. Psychological Bulletin, 121, 65-94.

Barkley, R. A. (2001). The inattentive subtype of ADHD as a distinct disorder. What remains to be done? Clinical Psychology: Science and Practice, 8, 489-493.

Barkley, R. (2006). Attention-deficit hyperactivity disorder: A handbook for diagnosis and treatment (3rd ed.). New York: Guilford Press.

Briand, K. A., Larrison, A. L., \& Sereno, A. B. (2000). Inhibition of return in manual and saccadic response systems. Perception and Psychophysics, 62, 1512-1524.

Castellanos, F. X, Giedd, J. N., Marsh, W. L., Hamburger, S. D., Vaituzis, A. C., Dickstein, D. P., et al. (1996). Quantitative brain magnetic resonance imaging in attention-deficit hyperactivity disorder. Archives of General Psychiatry, 53, 607-616.

Castellanos, F. X., \& Tannock, R. (2002). Neuroscience of attention-deficit/hyperactivity disorder. Nature Reviews: Neuroscience, 3, 617-628. and intentionally controlled mechanisms of attention the study demonstrates differences among the subtypes in terms of the degree to which these mechanisms might be deficient in their control of attention. Such a basic, bottomup analysis of attention is important because it could account for differences in the clinical profile among the subtypes, especially with regard to problems of attention. Further, the present findings have implications for assessing the clinical efficacy of treatments for ADHD. Separate assessment of intentional and reflexive mechanisms of attention might prove particularly useful in evaluating the clinical response to existing and new pharmacotherapies and behavioral interventions. At present, it is unclear if intentional and reflexive mechanisms might differ in their responsiveness to the beneficial effects of such treatments.
Clohessy, A. B., Posner, M. I., Rothbart, M. K., \& Vecera, S. P. (1992). The development of inhibition of return in early infancy. Journal of Cognitive Neuroscience, 3, 345-350.

Conners, C. K. (1990). Conners Rating Scales manual. New York: Multi-Health Systems.

Diamond, A. (2005). Attention-deficit disorder (attentiondeficit/hyperactivity disorder without hyperactivity): A neurobiologically and behaviorally distinct disorder from attention-deficit/hyperactivity disorder (with hyperactivity). Development and Psychopathology, 17, 807-825.

Durston, S., Thomas, K. M., Yang, Y., Ulug, A. M., Zimmerman, R. D., \& Casey, B. J. (2002). A neural basis for the development of inhibitory control. Developmental Science, 5, F9-F16.

Faust, M. E., \& Balota, D. A. (1997). Inhibition of return and visuospatial attention in healthy older adults and individuals with dementia of the Alzheimer type. Neuropsychology, 11, 13-29.

Fielding, J., Georgiou-Karistianis, N., Bradshaw, J., Millist, L., Churchyard, A. \& White, O. (2006). Accelerated time-course of inhibition of return in Huntington's disease. Behavioural Brain Research, 166, 211-219.

Fillmore, M. T., Rush, C. R., \& Abroms, B. D. (2005). $d$-Amphetamine-induced enhancement of inhibitory mechanisms involved in visual search. Experimental and Clinical Psychopharmacology, 13, 200-208.

Gouzoulis-Mayfrank, E., Arnold, S., \& Heekeren, K. (2006). Deficient inhibition of return in schizophrenia-Further evidence from an independent sample. Progress in Neuro-Psychopharmacology and Biological Psychiatry, 30, 42-49.

Hanisch, C., Radach, R., Holtkamp, K., Herpertz-Dahlmann, B., \& Konrad, K. (2006). Oculomotor inhibition in children with and without attention-deficit hyperactivity disorder (ADHD). Journal of Neural Transmission, 113, 671-684.

Huang-Pollock, C. L., Carr, T. H., \& Nigg, J. T. (2002). Development of selective attention: Perceptual load influ- 
ences early versus late attentional selection in children and adults. Developmental Psychopathology, 38, 363 375.

Huang-Pollock, C. L., Nigg, J. T., \& Carr, T. H. (2005). Deficient attention is hard to find: Applying the perceptual load model of selective attention to attention deficit hyperactivity disorder subtypes. Journal of Child Psychology and Psychiatry, 46, 1211-1218.

Klein, C. H., Raschke, A., \& Brandenbusch, A. (2003). Development of pro- and antisaccades in children with attention-deficit hyperactivity disorder (ADHD) and healthy controls. Psychophysiology, 40, 17-28.

Klein, R. M. (1988). Inhibitory tagging system facilitates visual search. Nature, 334, 430-431.

Klein, R. M. (2000). Inhibition of return. Trends in Cognitive Science, 4, 138-147.

Klein, R. M., \& MacInnes, W. J. (1999). Inhibition of return is a foraging facilitator in a visual search. Psychological Science, 10, 346-352.

Leth-Steensen, C., Elbaz, Z., \& Douglas, V. I. (2000). Mean response times, variability and skew in the responding of ADHD children: A response time distributional approach. Acta Psychologica, 104, 167-190.

Li, C. R., Chang, H., \& Lin, S. (2003). Inhibition of return in children with attention hyperactivity disorder. Experimental Brain Research, 149, 125-130.

Logan, G. D. (1994). On the ability to inhibit thought and action: A user's guide to the stop-signal paradigm. In D. Dagenbach \& T. H. Carr (Eds.), Inhibitory processes in attention, memory, and language (pp. 189-239). San Diego, CA: Academic Press.

Logan, G. D., \& Cowan, W. B. (1984). On the ability to inhibit thought and action: A theory of an act of control. Psychological Review, 91, 295-327.

Logan, G. D., \& Irwin, D. E. (2000). Don't look! Don't touch! Inhibitory control of eye and hand movements. Psychonomic Bulletin and Review, 7, 107-112.

Lorch, E. P., Berthiaume, K., Milich, R., \& van den Broek, P. (2007). Story comprehension impairments in children with ADHD. In K. Cain \& J. Oakhill (Eds.), Cognitive bases of children's language comprehension difficulties (pp. 128-155). New York: Guilford Press.

Lorch, E. P., Sanchez, R., van den Broek, P., Milich, R., Murphy, E. L., Lorch, R., et al. (1999). The relation of story structure properties to recall of television stories in young children with attention deficit hyperactivity disorder and nonreferred peers. Journal of Abnormal Child Psychology, 27, 293-309.

Luna, B., Garver, K. E., Urban, T. A., Lazar, N. A., \& Sweeney, J. A. (2004). Maturation of cognitive processes from childhood to late adulthood. Child Development, 75, 1357-1372.

Lupianez, J., Milan, E. G., Tornay, F. J., Madrid, E., \& Tudela, P. (1997). Does IOR occur in discrimination tasks? Yes, it does, but later. Perception and Psychophysics, 59, 1241-1254.

Lupianez, J., Milliken, B., Solano, C., Weaver, B., \& Tipper, S. P. (2001). On the strategic modulation of the time course of facilitation and inhibition of return. Quarterly Journal of Experimental Psychology A: $\mathrm{Hu}$ man Experimental Psychology, 54A, 753-773.

Lynam, D. R. (1996). The early identification of chronic offenders: Who is the fledgling psychopath? Psychological Bulletin, 120, 209-234.

Marzi, C. A. (1999). Neuropsychology of attention. In G. Denes \& P. Luigi (Eds.), Handbook of clinical and experimental neuropsychology (pp. 509-524). Hove: Psychology Press/Erlbaum/Taylor \& Francis.

Mayer, A. R., Seidenberg, M., Dorflinger, J. M., \& Roa, S. M. (2004). An event-related fMRI study of exogenous orienting: Supporting evidence for the cortical basis of inhibition of return? Journal of Cognitive Neuroscience, 16, 1262-1271.

Milich, R., Balentine, A. C., \& Lynam, D. R. (2001). ADHD combined type and ADHD predominantly inattentive type are distinct and unrelated disorders. Clinical Psychology: Science and Practice, 8, 463-488.

Miller, J., Schaffer, R., \& Hackley, S. A. (1991). Effects of preliminary information in a go versus no-go task. Acta Psychologia, 76, 241-292.

Nigg, J. T. (2006). What causes ADHD? Understanding what goes wrong and why. New York: Guilford Press.

O'Driscoll, G. A., Depatie, L., Holahan, A. V., SavionLemieux, T., Barr, R. G., Jolicoeur, et al. (2005). Executive functions and methylphenidate response in subtypes of attention-deficit/hyperactivity disorder. $\mathrm{Bi}$ ological Psychiatry, 57, 1452-1460.

Oosterlaan, J., \& Sergeant, J. A. (1996). Inhibition in ADHD, aggressive, and anxious children: a biologically based model of child psychopathology. Journal of Abnormal Child Psychology, 24, 19-37.

Posner, M. I., \& Cohen, Y. (1984). Components of visual orienting. In H. Houma \& D. G. Bouwhuis (Eds.), Attention and performance $X$ : Control of language processes (pp. 531-556). Hillsdale, NJ: Erlbaum.

Posner, M. I., Rafal, R. D., Choate, L. S., \& Vaughan, J. (1985). Inhibition of return: Neural basis and function. Cognitive Neuropsychology, 2, 211-228.

Ro, T., Farne, A., \& Chang, E. (2003). Inhibition of return and the human frontal eye fields. Experimental Brain Research, 150, 290-296.

Rommelse, N. N. J., Deijen, J. B., Geldof, C. J. A., Witlox, J., Oosterlaan, J., \& Sergeant, J. A. (2007). Oculomotor capture in ADHD. Cognitive Neuropsychology, 24, 535-549.

Schachar, R. J., \& Tannock, R. (1995). A test of four hypotheses for the comorbidity of attention deficit hyperactivity disorder and conduct disorder. Journal of the American Academy of Child \& Adolescent Psychiatry, 34, 639-648.

Schachar, R., Tannock, R., Marriott, M., \& Logan, G. (1995). Deficient inhibitory control in attention deficit hyperactivity disorder. Journal of Abnormal Child Psychology, 23, 411-437.

Schall, J. D. (2004). On the role of frontal eye field in guiding attention and saccades. Vision Research, 44, 1453-1467.

Schneider, W., Eschman, A., \& Zuccolotto, A. (2002). EPrime user's guide. Pittsburgh, PA: Psychology Software Tools.

Shimojo, S., Hikosaka, O., \& Miyauchi, S. (1999). Automatic and controlled attention detected by the line motion effect. In G. Daniel \& A. Koriat (Eds.), Attention and performance: Vol. 17. Cognitive regulation of performance: Interaction of theory and application (pp. 145-163). Cambridge, MA: MIT Press.

Tannock, R. (1998). Attention deficit hyperactivity disorder: Advances in cognitive, neurobiological, and genetic research. Journal of Child Psychology and Psychiatry, 39, 65-99.

Weller, E. B., Weller, R. A., Rooney, M. T., \& Fristad, M. A. (1999). Children's interview for psychiatric syndromes. Washington, DC: American Psychiatric Association. 